\title{
The Authorship Process from the Perspective of Discourse Analysis Anchored in the Brazilian National Common Core Curriculum
}

\author{
Valéria André dos Santos ${ }^{\mathrm{a}}$, Júlio César Andréb*, Loiane Letícia dos Santos ${ }^{\mathrm{c}}$, Lorena Aline \\ Santos Almeida ${ }^{\mathrm{d}}$, Eliane Luiz dos Santos ${ }^{\mathrm{a}}$, Talessa L. F. Bromate ${ }^{\mathrm{a}}$, Randolfo dos Santos Júnior ${ }^{\mathrm{e}}$ \\ aState School “Rui Barbosa”, GlóriaD’Oeste, MatoGrosso, Brazil \\ bCenter for the Study and Development of Health Education-CEDES, Medical School of Medicine of São José \\ do Rio Preto - FAMERP, Brazil \\ cMunicipal Institute of Education of Catanduva - IMES, Catanduva, São Paulo, Brazil \\ dDoctor, Blumenau, Santa Catarina, Brazil
}

eDepartment of Psychology and Psychiatry, Medical School of Medicine of São José do Rio Preto - FAMERP, Brazil

*Corresponding Author: Júlio César André, Center for the Study and Development of Health Education - CEDES, Medical School of Medicine of São José do Rio Preto - FAMERP, Brazil

\begin{abstract}
This article aims to present a practice of reading and writing in the discursive perspective, from versions of literature in the reconstruction of stories, focusing on authorship. The theoretical basis that supports this reflection is Discourse Analysis (DA), anchored in the studies of Michel Pêcheux, in France, and EniPuccinelli Orlandi, in Brazil, the Brazilian National Common Core Curriculum(BNCC) and the Curriculum Reference Document of MatoGrosso (CRD-MT). The purpose was to work on the literary work discursively, developing skills and abilities through activities that led to the establishment of relations of similarities and differences between these materials, in which we gave visibility to the effects of meaning produced, considering the different processes of constitution, formulation and circulation of different significant materiality as a final product. The activities were carried out between 2019 and 2020, at the State School "Rui Barbosa", Monte Castelo district - Brazil, through a reading project which started in 2012 and that has been gradually improving, but has shown that it is worth investing in different classroom practices and making a significant contribution so that everyone who participates in it promotes intellectual growth and expands the perspective of the future foreseen in the educational perspective.
\end{abstract}

Keywords: Reading, Authorship, Writing, Discourse Analysis, Effects of Meaning, Significant Materialities.

\section{INTRODUCTION}

The school must consolidate in its pedagogical proposal the National Common Core Curriculum (BNCC) [1] in order to offer and guarantee a quality education based on legal parameters that guide its pedagogical practice. By implementing and following these skills and abilities, the school treads its path, respecting all the specificities existing in the school space, and thus, welcomes all children, young people and adults with respect and adequate attention so that everyone has equal access and permanence at school, forming critical citizens capable of acting in the transformation of society [2].

Since the beginning of school life, we, as teachers, paraphrasing Orlandi [3], need to problematize the ways of reading, showing the conditions of production in which this reading is inserted, to lead the speaking subject or reader to reflect on issues that he produces, sees and hears in the different manifestations of language. "Reading is a practice that presupposes the subject's history and work of discursive memory in which the senses are produced in relation to the conditions of production" [4]. The real thing in the classroom is heterogeneity, instability, controversy, litigation, difference; this space needs to be flooded with texts of different significant materiality [5], which circulate in different ways, which can refer the student to a place populated by several voices, in which the senses are plural. Thus, there will be space for controversial discourse in which the discursive object is at 
stake, in a situation of dispute and, thus, to be desired, written and spoken by students and teachers, understood here as subjects of language [6].

In this sense, the BNCC and the Brazilian Constitution, from which it emanates, highlights:

"Article 206. Teaching shall be conducted on the basis of the following principles: equal conditions for access and permanence at school; freedom to learn, teach, research and disseminate thought, art and knowledge; pluralism of ideas and pedagogical concepts, and the coexistence of public and private educational institutions, free public education in official establishments; democratic management of public education in accordance with the law; quality standard guarantee [7]."

"Art. 26 The curricula of elementary and secondary education must have a common national core, to be complemented, in each education system and school establishment, by a diversified part, required by the regional and local characteristics of society, culture, economy and clientele". $\S 1^{\circ}$. The curricula referred to in the caput must cover, necessarily, the study of the Portuguese language and mathematics, the knowledge of the physical and natural world and the social and political reality, especially in Brazil [1]."

The teaching of the Portuguese language is very rooted in practices anchored in teaching programs, teaching instruments (grammars, textbooks, dictionaries, etc.) and the regulations that constitute a discursive formation that gives cohesion to an subject-form and a conception of what it means about language and knowing the language and those practices already saturated in the classroom have become naturalized in such a way that the students' relationship with the Portuguese language does not allow the student/subject to mean it and, in this sense, their relationship with reading takes place only in the description and contemplation of the language [8]. These practices are rooted in the Middle Ages, when only clerics were allowed to read, speak and write in their names, and the set of all others, whose tirelessly repeated gestures of copying, transcribing, extracting, classifying, indexing, coding constituted a reading of the subject's erasure behind the institution that employed him. We see this issue in close relation to the notion developed by Pêcheux regarding the division of the social work of reading $[9,10]$.

According to Sairan [11], the naturalization process of intellectual work circumscribes, on the one hand, the university professor, the critic, the researcher, in the domain of knowledge, being granted "the right to produce original readings, therefore , interpretations", and, as such, are authorized and legitimized to prepare the textbook; on the other hand, in the domain of doing, the subjects of schooling, the teachers and students of the school are enrolled, to whom is assigned "the subordinate task of preparing and sustaining, by the anonymous gestures of literal treatment" of the documents, the said interpretations ..."[12]. The result of this practice keeps the student alienated, in a position subjected only to receiving the contents, and not even participating as protagonist subjects in the institution's propositions. That is why, perhaps, the speech of preparing for the job market is presented, as there, too, there would be a passive performance, only receiving commands [13]. The school produces the imaginary of the place of formation of subjects of knowledge, who act in the transformation of society. To this end, it should provide an opportunity for the subject to actively participate in all actions promoted within the scope of the teaching processes and political actions of the school.

The Curriculum Reference Document (CRD) of Mato Grosso [14] emphasizes active learning, as a proposal for the pedagogical action that comes from the change in the educational paradigm in which the centrality is in learning by doing and, above all, in the collaborative way of doing under the mediation of a teacher [15]. In this perspective, learning is never passive, it is always on the move [16], it is mobilized and becomes a mobilizer of authorship of the subjects in the training process, as it is linked to the aim of making the student a competent subject for problem solving in different fields of everyday life. The student assumes the position of author, in which he controls the senses, in which he ties an imaginary of beginning, middle and end, subverting order and taking responsibility for his speech. We made these considerations to support the fundamental aim of the project, which is to work on reading and writing in the discursive perspective to develop the training of readers and authors, through the constitution of a reading file, based on literature, in (re)construction of stories, in order to 
give the possibility of authorship to my students, that is, to carry out the "transition", from oral to written, when assuming their saying, placing themselves in this process. As Gallo [17] states, in the "position" of those who write a text (at the moment when the students establish the relationship between the plot and the outcome) in the school space.

In this sense, the study aimed to develop a practice of reading and writing in the discursive perspective, from versions of literature for the theater in the reconstruction of stories or in the form of videos. The theoretical framework that supported this reflection is Discourse Analysis (DA), anchored in the studies of Michel Pêcheux, in France, and EniPuccinelliOrlandi, in Brazil, the Brazilian National Common Core Curriculum (BNCC) and the [CRD].

\section{Methodology}

\subsection{Project Steps}

At first, the systematic consisted of the gradual reading of books chosen by the students themselves in a receptive manner and that broke with their universe of expectations, based on linguistic marks, on their knowledge of the genre and the theme. For this purpose, two or more copies of each title available in the collection of the school library were delivered, so that they could talk about it and elaborate questions among the pairs, thus ending with the personal choice, where the 2 or more students who chose the same title became a book partner(s). The reading was then done autonomously, accompanied by understanding, selecting procedures and reading strategies appropriate to different aims and taking into account characteristics of the genres and supports (children's and youth novels, folk tales, tales of terror, Brazilian legends, indigenous and Africans, adventure narratives, enigma narratives, myths, chronicles, autobiographies, comic books, mangá comic strip of Japanese origin), free and fixed poems such as sonnets and twine, video poems, visual poems, among others) expressing an assessment of the text read and establishing preferences for genres, themes, authors [2].

This was followed by knowledge of the materiality, the conditions of production, the said and the unsaid, using the filling in of the catalog. The next step consisted of illustrating the book according to the impressions produced and what the title suggested. Subsequently, weekly meetings were held in which there was an exchange of questions, previously elaborated, to the book partner(s) about the same. A new step consisted of counting the excerpt read orally, using appropriate tools to support oral presentations [1], followed by the preparation of the critical summary, based on the notes or diagrams made and the preparation of the final product, which consisted of a fragment of the books read, to be inserted together with the presentations of the reading project that already happens at school.

The elaboration of the theatrical text, based on the adaptation of romances, short stories, enigma and adventure narratives, novels, among others, explaining the physical and psychological characterization of the characters, indicating the rubrics for characterizing the scenario, space and time, retextualizing the treatment of the theme [1], preceded the production of scripts for the elaboration of videos specific to youth cultures in view of the viewers, the aim, the conditions of production, vehicles and circulation media, from the book read [1].Then there was the representation of dramatic scenes or texts, considering, in the characterization of the characters, the linguistic and paralinguistic aspects of the speeches (timbre and tone of voice, pauses and hesitations, intonation and expressiveness, linguistic varieties and registers), gestures and displacements in the scenic space, the costumes and makeup and elaborating the rubrics indicated by the author through the scenery, the soundtrack and the exploration of the interpretation modes [2].

Of paramount importance, it was the step that consisted of the inference of the presence of social, cultural and human values and different views of the world in literary texts as well as the last step, which was dedicated to the evaluation "in order to establish the point from where the subject of the experiment started and suffered a change after the process" [17].

\section{RESUlts}

At the State School "Rui Barbosa", as an example of part of the practices already adopted by the school, which seeks to meet the CurriculumInstructionof the State of MatoGrosso, the reading project: "Reading, telling and retelling", started in 2012 , from a concern: that students had difficulties in writing and interpreting text in all school subjects. The school and, more precisely, the Portuguese 
language teachers, have been conducting this project since then, which has as a stimulus a tour for those who read and review at least one book every two months. The methodology used, first, consists of the reading of different novels and, in a second moment, of the production of a critical review, to verify the content read, resulting in theaters or videos. This form of effective verification of the reading practice reflected in the writing has shown us that the ways of reading are in no way disconnected from the writing practices.

Therefore, the more the student reads, the better conditions they have to write. Reading is a free choice and has been affecting more and more students and causing improvement in writing production, understanding of the world and criticality, being visibly perceived in the summaries of the books produced, giving an effect of completeness with regard to the aims from the project.

The choice of books by the students themselves, based on linguistic marks, on their knowledge of the genre and on the theme, showed us that the ways of reading are in no way disconnected from writing practices. In our imagination, the more the student reads, the better conditions they have to write.

It was possible to create a reading file, through the preparation of summaries of book chapters, the production of drawings, records of discussions and notes, making it possible to produce a new text and thus allowing gestures authorship of students and the transformation of the learner.

It was possible to analyze in fictional narrative texts, the different forms of composition specific to each genre, based on linguistic marks, on the theme of these productions that represent a challenge in relation to their current possibilities and their previous reading experiences..

There is a difference between students who live in the urban area, in the district, those who live in the rural area, who are called "hick", "uneducated", but it is possible to observe that, among the readers of the school, half of themis from rural area and the other half is from the urban area. As for discipline and interest, rural students stand out more, eagerly seek education as a way to improve their lives, go to college and return as members of the school's staff.

Thus, a work was carried out according to the theoretical bases ofDA, taking into account that the subject-reader has its specificities, its reading history, its particularity.

\section{DISCUSSION}

In this perspective, the State School "Rui Barbosa" can be seen as a starting point, namely: it must guide its pedagogical administrative action through this Project, a collective construction document, politically committed to the National Curriculum Guidelines and the Curriculum Instruction for Basic Education of MatoGrosso [14], which reads: "it is committed to ensure education with social quality, providing the student with the development of skills and the construction of knowledge for the formation of human values in the achievement of full citizenship".

After beginning the readings in the discursive perspective, it was understood that when analyzing the pages of a book, the project: "Reading, telling and retelling", refers to the main ideas of the text or to the author's intention, through content questions related to cohesion and coherence that leave aside questions that lead us to another reading path, which distrusts everything that can be stated as obvious, for example: "what does this text not discuss?" [18] and that could be more relevant and interesting to the understanding and interest of the readers. For DA, reading is understood as the production of meanings, due to the fact that the subject-reader, constituted by these effects, represents the conjunction of two historicities: the history of his (the reader's) readings and the history of readings of the text [...] that act dynamically in the constitution of 'their' specific reading, at a given moment [20].

In this sense, there is a need to: "Offer students elements to discuss the conditions of production of the various speeches so that they may question them, so that the other historical senses are also evidenced and they move and occupy another subject position. For DA, displacement is in the possibility of producing effects of different senses from those stabilized in their social group [20]. Thus, through work with and in difference, to promote displacements in this way of reading, we aim to provide conditions for students to tell themselves and appropriate different materials to expand their reading repertoire and to produce the bond teacher-student / knowledge: "In the symbolic work structured in incompleteness and contradiction, the images, words, gestures, sounds, music make up drift possibilities and let us see the difference in their potential to bring out the political in the social" [21]. 
According to DA, reading is concerned with the meaning, not the literal form, exclusivity of the teacher or the author. From this perspective, it is not possible to silence other possibilities of interpretation and, in this way, the teacher can modify the conditions of production of the student's reading: on the one hand, allowing him to build his reading history; on the other, establishing, when necessary, intertextual relations, rescuing the history of meanings in the text [3]. Discourse analysis can be understood as a "theory of interpretation" that seeks, from its origin, to understand "how a text means", reflecting on "how" it is constituted with its production conditions and how the effects of sense, becoming fundamental in this transformation process. In this theory, "it is considered that reading is produced and one seeks to determine the process and conditions of its production" [22], conditions that need to consider the subjects (author and reader), the ideology, the different types of discourse, the distinction between paraphrastic and polysemic reading, in order to install new meanings in the classroom, displacing the student from the place of a mere recipient of already legitimated content and meanings and signaling the possibility of expression, questions and doubts.

Before knowing the theory, he believed that reading should always be verbal language; after studies in Discourse Analysis, the importance of visual and sound language was also discovered, with the aim of exploring the details of a scene and verifying how symbolic objects produce effects of meaning [3]. And that was how a result was reached: in a succession of readings from the book, films and drawings and discussions about the meaning effects of each and everyone among them that it was possible to build the final product. A new version of the Peter Pan story, bringing this story to the present day, presented on a festive night for the school community, showing the effects of authorship: "The author is, therefore, the subject who, having mastered certain discursivemechanisms, represents, through language, this role, in the social order in which it is inserted" [19].

Therefore, we believe it is necessary to form a reading file, so that, in this activity, "students begin to place themselves in the condition of authorship, assuming a social role in relation to language in front of the school institution" [19 ]. To teach reading, it is necessary to allow the reader to work with what he does not know. Reading can be thought of precisely as the construction of this relationship between discourse and text and this is where the teacher can provide elements for the learner reader [23]. The set of readings made by the students partly configures the comprehensibility of each specific reader and it is important to reflect on the possibility of reading being worked on, that reading is part of the process of establishing the senses and that we are exposed to it all the time and our student too, but what differentiates us from each other is the uniqueness and the way each subject positions himself in front of an object to be read and interpreted, registered through writing or other circulation media. In other words, the reading is crossed by the discursive memory of the previous readings made by the subject or by other readers, as they produce effects resulting from the crossing of others. Therefore, what remains for us is that it is the way the teacher provides the conditions for the production of reading in the school context that will enable students to read in a way that new senses will be produced. The constitution of the reading file included the elaboration of the text in a reflexive way in which they were able to exercise a revealing criticism of the relativity of the sense of the text and of its institutionalization on the other, building a certain direction, leaving aside many possible directions that its history could have taken [17]. There was space for writing, rewriting, proofreading, rehearsal for staging, making posters and invitations, printed and/or handwritten, according to the conditions requested. Each group, based on the thematic axis of their preference, announced at the first meeting with the class, in the conversation circle (magic, love, comedy and adventure), wrote their text, taking into account the authorship: "the subject only signs himself as an author if what he produces is interpretable "[24]. This is how we understand that we are creating the possibilities for the slippage of sense, so that students re-signify what has already been said, becoming authors of this process. The students managed to make this "passage", from the moment they became authors of the play and the videos, produced, reviewed and presented by them, from the readings.

By creating a space in which historical repetition takes place based on what students already know for the elaboration of other forms of effective knowledge in their conditions, based on clippings from certain areas of the interdiscourse, which allow recognition, as stated by Hashiguti [4], "the ludic discourse in which the interlocutors are exposed to the referent with the circulation of senses, that is, the open polysemy". It is in this polysemy that the subject-teacher and student positions act. Misunderstanding is the only certainty. The best certainty. Many senses can be made possible in this 
relationship. They are the materializations of the constitution of history [25]. The teacher's doing needs to be nurtured by a theory; this relationship is built as the teacher reads, is challenged, looks at his practice, evaluates, establishes relationships, exchanges experiences with colleagues and recognizes himself as capable of changes: The teacher can modify the conditions of production of the student's reading: on the one hand, allowing him to build his reading history; on the other, establishing, when necessary, intertextual relations, rescuing the history of the text's meanings [3].

\section{CONCLuSion}

When carrying out a work according to the theoretical bases of DA, taking into account that the subject-reader has his specificities, his reading history, his particularity made it possible to create a space in which the historical repetition happened from what the students already know for the elaboration of other forms of effective knowledge in their conditions, from clippings of certain zones of the interdiscourse, that allow recognizing

BNCC defends pedagogical proposals that are attentive to the progression and full development of the student as an integral and protagonist of social practices in the various fields of activity and CRD active learning. With these three pedagogical aspects, it is possible to carry out this project, which is already a pilot in the municipality and serves as a model for other institutions.

As expressive results, it was possible to verify that the number of students who sought higher education at the end of high school, after the implementation of the project was significant; this is due to the discovery of new perspectives for improvements that reading arouses. Another fact that deserves mention is that several of our students achieved a significant score in the writing of the National High School Exam (ENEM) in Brazil, as a probable result of reading that increased their vocabulary repertoire, their criticality and worldview.

Another achievement is that some students make reading a habit even without participating in the awards, demonstrating that the objective of the project has been achieved: to create a reading audience. We were grateful to have students who live in risky situations as readers and that reading helped them to have new perspectives, since the project also gives students the opportunity to have a moment of leisure and culture in addition to books and the space in which they live. In the two previous editions, students who won first, second and third place were entitled to a cultural trip to São Paulo, the Brazilian cultural capital, with air transportation (an almost material unreality for subjects with these social and economic origins) to get to know the main tourist spots, sponsored by an anonymous person who already finances the medals for believing it is essential to encourage a project of this importance for the school community and society.

It is worth remembering that it is not possible to invent a recipe. Our project is unique and even if someone wants to copy it, that is, use the same methodology, the results will be different, because the subjects will not be the same, the production conditions will be different, the time will be different, the teacher will be another, activities may be different, etc. It is the production conditions in which the activities were designed and the chosen class that will provide the different in any proposal. It is the way in which the conditions for the production of reading are made available, in a process of reframing the social division of this work that will arise the interest of students, since the senses are not unique, nor should they be administered in the classroom. It is in this way that we understand the constitution of students' authorship in relation to the production of reading and writing, so that their sayings can be legitimized.

The development of the project described herein has shown that it is worth investing in differentiated classroom practices considering its significant evolution. In this perspective, the role of teachers in learning is that of mediator, stimulator of ideas and connections for the promotion of active learning. Knowing students about their interests, cultures, learning styles favors a relationship between teacherstudent of security and confidence in learning ability, with the aim of integrating them into their differences. Thus, we believe that the continuity of this project should contribute significantly so that everyone who participates in it will promote intellectual growth and expand the perspective of the future from an educational perspective.

\section{REFERENCES}


[1] Brasil, Base Nacional Comum Curricular. Brasília: MEC, 2017.

[2] Projeto Político Pedagógico (PPP), Escola Estadual Rui Barbosa. Monte Castelo do Oeste, MT, 2016.

[3] E. P. Orlandi, Discourse analysis: principles and procedures, 9th ed. Campinas, SP: Pontes, 2015.

[4] S. T. Hashiguti, nas teias da leitura. In: C. Z. Bolognini, C. Pfeifer e S. Lagazz (Orgs.), Práticas de linguagem na escola. Campinas: Mercado das letras, 2009, pp. 19-38. (Série Discurso e Ensino).

[5] C. P. Fedatto e C. P. Machado, C. P, The wall, courtyardand coral orthesenses in/oftheteacher. In C. Z. Bolognini (Org.), Speech and teaching: cinema at school. Campinas, SP: Mercado de Letras. 2007, pp. 916.

[6] E. P. Orlandi, Neither writer nor subject: only author. In E. P. Orlandi, Speech and São Paulo: Cortez, 1993, pp. 183-194.

[7] Brasil, Senado Federal, Constituição da República Federativa do Brasil: texto constitucional promulgado em 5 de outubro de 1988, com as alterações determinadas pelas Emendas Constitucionais de Revisão nos 1 a 6/94, pelas Emendas Constitucionais nos 1/92 a 91/2016 e pelo Decreto Legislativo no 186/2008. Brasília: Senado Federal, Coordenação de Edições Técnicas, 2016.

[8] A. M. Di Renzo, school and the formulation of linguistic policies, Rev. Letras Univ. Brasília, 1 (2), 5-15 (2008).

[9] M. Pêcheux, Read the file today. In E. P. Orlandi (Org.), Reading gestures: from the story in the speech. Campinas: Editora da Unicamp, 1994, pp. 49-59.

[10] M. Pêcheux, Semantics and discourse: a critique of the affirmation of the obvious, $2^{\mathrm{a}}$ ed. Campinas: Edunicamp, Unicamp, 1995.

[11] M. C. Sairan, The injunction to the new and the repetition of the old: a discursive view of the Program Um ComputadorporAluno (PROUCA), Ph.d. Thesis. Instituto de Estudos da Linguagem, Universidade Estadual de Campinas. Campinas, SP. Pp. 266 (2012).

[12] M. Pêcheux, The discourse: structure or event, 4th ed. Campinas: Pontes, 2006.

[13] E. C. Dalcico (2015). New gestures of interpretation: the challenge of "teaching" how to read, Ph.d. Thesis. Universidade do Estado de Mato Grosso. Mato Grosso, MT. Pp. 122 (2015).

[14] Secretaria de Estado de Educação de Mato Grosso, Curriculum guidelines: conceptions for basiceducation. Cuiabá, MT: SEDUC/MT, 2010.

[15] O. JEREZ, F. Coronado, G. VALEnZUELA, G, A Development Model of Social responsibility Competencies for Sustainable Development in the School of Economics and Business of the University of Chile. In F. Gonçalves, R. Pereira e W. Leal. Switzerland: Bern, 2010, p. 899-911.

[16] O. JEREZ, Comprendiendoel Enfoque de Competencias. Santiago: CorporaciónSofofa, 2008.

[17] S. L. Gallo, Teaching of written language $x$ teaching of written speech, Ph.d, UniversidadeEstadual de Campinas. Campinas, SP. Pp. 148 (1990).

[18] S. Lagazzi-Rodrigues, S, Discourse analysis: significant materiality in history. In A. Di Renzo, A. L. A. Rodrigues e T. Pitombro (Orgs.), Language, history and memory: moving speeches. Campinas: Pontes, 2011, pp. 275-290.

[19] E. P. Orlandi, Speech and Reading, 9th ed. São Paulo: Cortez, 2012.

[20] C. Z. Bolognini e C. L. S. Pfeifer (Orgs.), Languagepracticesatschool. Campinas: Mercado das Letras, 2009.

[21] S. Lagazzi-Rodrigues, The discourse in different territories: the red among all colors. In S. O. Maluf, V. Silva, E. Almeida e L. S. J. Bisinoto (Orgs) Speech, subject and memory. Campinas: Pontes. 2012, pp. 133-146.

[22] E. P. Orlandi, Neither writer nor subject: only author. In: E. P. Orlandi, Speech and Reading. São Paulo: Cortez. 1993, pp. 183-194.

[23] E P. Orlandi, Speech and text: formulation and circulation of the senses, 3rd ed. Campinas, SP: Pontes, 2012.

[24] E. P. Orlandi. Language and its functioning: the forms of discourse, 5th ed. Campinas, SP: Pontes, 2009.

[25] C. P. Fedatto e R. Bezerra, Land of Never and Truth - the history of the senses. In C. Z. Bolognini (Org.), Speech and teaching: reading in cinema, $1^{\mathrm{a}}$ ed. Campinas, SP: Mercado de Letras, 2011, pp. 31-38.

\section{AUTHOR'S BIOGRAPHY}

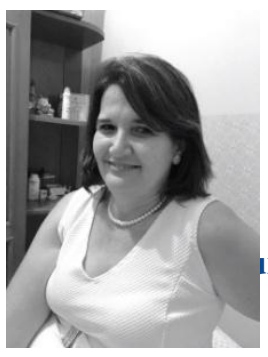

Valéria André dos Santosa, Licensed in Literature (1997), Professor in the State of MatoGrosso in the area of Portuguese Language (2000), Specialization in Portuguese Language and Literature (2001), Master in Letters, PROFLETRAS (2016). Creator and executor of the Reading Project entitled "Ler, Contar e 
Recontar" at the Rui Barbosa State School - GlóriaD’Oeste - MT, since 2012, a project resulting from the identification of the difficulties presented by students in reading, writing and text interpretation. Its positive results have been the reason for its continuity and the professional and human motivation of the author.

Citation: Valéria André dos Santos, et.al. "The Authorship Process from the Perspective of Discourse Analysis Anchored in the Brazilian National Common Core Curriculum" International Journal of Humanities Social Sciences and Education (IJHSSE), vol 7, no. 4, 2020, pp. 110-117. doi: http://dx.doi.org/10.20431/2349-0381.0704011.

Copyright: (c) 2020 Authors. This is an open-access article distributed under the terms of the Creative Commons Attribution License, which permits unrestricted use, distribution, and reproduction in any medium, provided the original author and source are credited. 